\title{
Biotransformation of ginsenoside using covalently immobilized snailase enzyme onto activated carrageenan gel beads
}

\author{
MOHAMED HASSAN ${ }^{1,2}$, XIAOKU RAN ${ }^{1}$, YING YUAN ${ }^{1}$, XIAONING LUAN ${ }^{1}$ \\ and DE-QIANG DOU ${ }^{1, *}$ \\ ${ }^{1}$ College of Pharmacy, Liaoning University of Traditional Chinese Medicine, Dalian 116600, People's Republic of China \\ ${ }^{2}$ Centre of Excellence, Encapsulation and Nanobiotechnology Group, Chemistry of Natural and Microbial Products \\ Department, National Research Centre, Dokki, Cairo 12622, Egypt \\ *Author for correspondence (deqiangdou@126.com)
}

MS received 29 January 2018; accepted 18 June 2018; published online 2 February 2019

\begin{abstract}
Ginsenoside transformation has received significant attention from scientists. The main objective of this study is to use immobilized enzymes in ginsenoside transformation. Factors affecting immobilization process were studied; carrageenan beads treated with polyethyleneimine and then activated using glutaraldehyde (GA) were used for snailase enzyme immobilization. The functionalized gel beads were characterized using Fourier transform infrared spectroscopy to verify the modification process. Furthermore, the optimum conditions for biotransformation of ginsenoside were also deliberated and showed that optimum biotransformation $\mathrm{pH}$ is 4.5 and 5-5.5 and temperature 50 and $60^{\circ} \mathrm{C}$ for free and immobilized snailase, respectively. Michaelis constants, $K_{\mathrm{m}}$ and $V_{\max }$, were also studied. The immobilized enzyme retains $96 \%$ of its initial activity after being used 10 consecutive times. The results clearly suggested that ginsenoside transformation was performed using immobilized snailase; this process can reduce the transformation cost as the enzyme can be reused many times.
\end{abstract}

Keywords. Panax ginseng; snailase enzyme; covalent immobilization; kinetic parameters; reusability.

\section{Introduction}

Ginseng, the roots of Panax ginseng Meyer, is one of the most important herbs in traditional medicine and has been used in Asia for thousands of years. Nowadays it is a famous drug worldwide [1]. Ginsenosides belonging to the group of triterpenoid saponins were regarded as one of the most effective components of ginseng. They are classified by their aglycones into two groups namely dammarane- and oleanane-type [2]. The dammarane-type can be classified into two types, one of them is the protopanaxadiol (PPD)-type ginsenoside (such as $\mathrm{Rb} 1, \mathrm{Rb} 2, \mathrm{Rc}$ and $\mathrm{Rd}$ ) and the other one is protopanaxatriol (PPT)-type ginsenoside (such as Re, Rf and Rg1) [3,4]. Previously the characteristic constituent of ginseng and its anti-cancer component was studied and the results showed that the secondary ginsenosides possess stronger anti-cancer activity [5].

Ginsenosides can be hydrolysed by using digestive enzymes or intestinal bacteria into secondary ginsenosides which is absorbed slowly in the gastrointestinal tract and exhibit physiological activity [6].

The secondary ginsenosides, which are present at low concentration in red ginseng and wild ginseng such as F2,
compound-K (C-K), compound-C-Mc (C-Mc), compound-Y (C-Y), Rg3, Rg2, Rh2, Rh1 and F1, could be produced by hydrolysing the sugar moieties of major ginsenosides, including Rb1, Rb2, Rc, Rd, Rf, Re and Rg1 [7-9].

Several years ago, various transformation techniques were used such as mild acid hydrolysis [10] and microbial conversion [11] to convert the primary ginsenosides to C-K. However, such transformation methods were time-consuming, and resulted in low selectivity and low-conversion rates; enzymatic transformation has been proposed as the most promising technique for the preparation of active components via choosing an enzyme that has high specificity, yield and productivity. Snailase, consisting of cellulase, hemicellulase, pectinase and $\beta$-glucuronidase [12], has received increased attention due to its stronger hydrolytic abilities. Recently, snailase has been reported in ginsenoside transformation by Wei et al [13].

To reduce the transformation cost, the enzyme immobilization technique was studied. There are various methods for enzyme immobilization such as adsorption, crosslinking, entrapment, encapsulation and covalent binding method [14]. The carrier also should be chosen carefully such that it has good mechanical strength, resistance to microorganisms, is cheap and has available functional groups on its large 


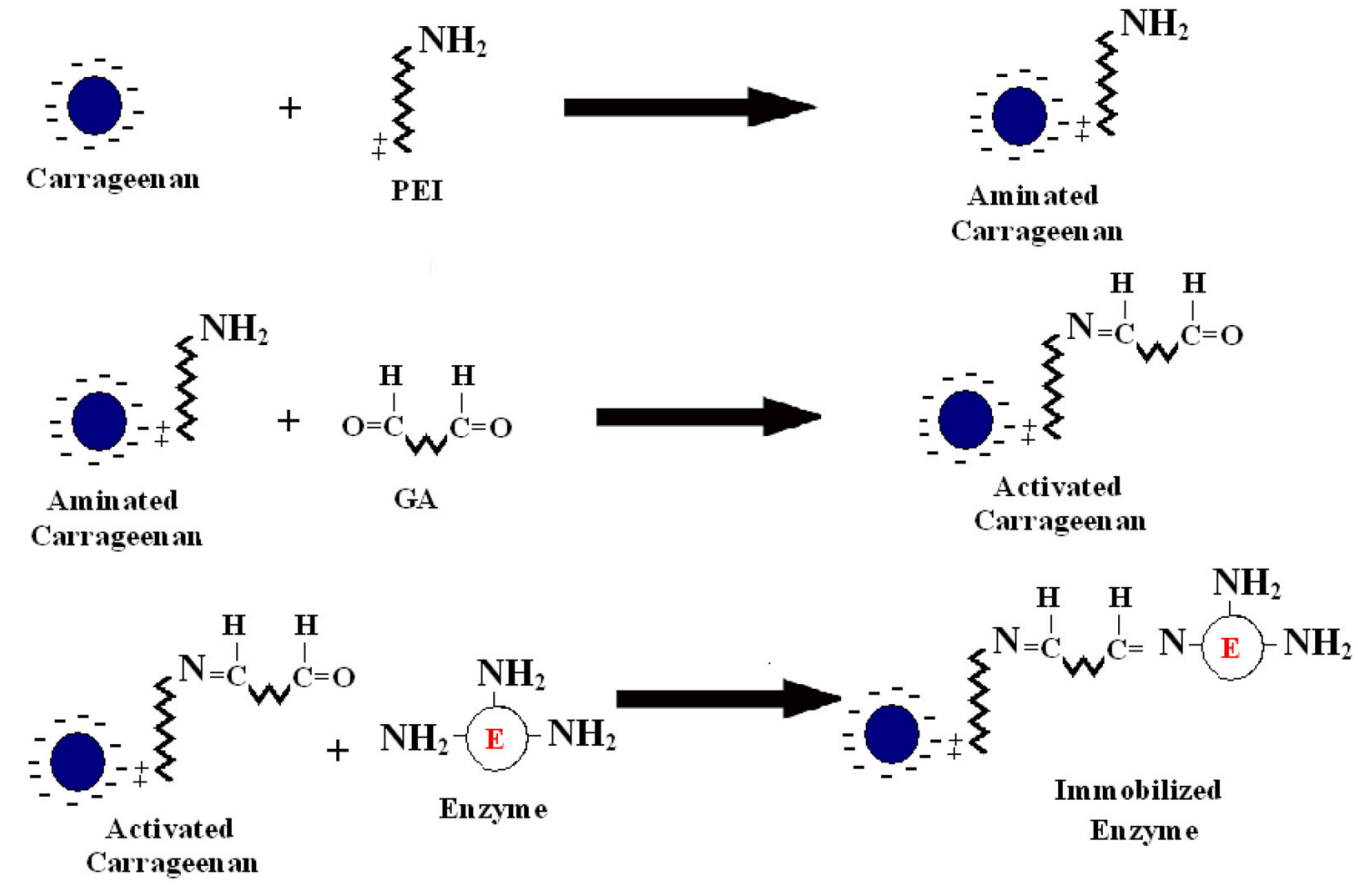

Figure 1. Schematic representation of carrageenan gel bead activation and enzyme immobilization.

surface area [15]. After immobilization of the enzyme to solid carrier, it could be used several times, revealing that the cost for transformation could be reduced.

In this research we studied the ginsenoside transformation by using immobilized snailase onto activated carrageenan gel beads. The optimum conditions of ginsenoside biotransformation were determined. The conversion of ginsenosides into $\mathrm{C}-\mathrm{K}$ was detected by using HPLC. The reusability of immobilized snailase was also tested to confirm the suitability of the beads for industrial use.

\section{Experimental}

\subsection{Materials}

Sodium alginate, $K$-carrageenan, chitosan, snailase enzyme and polyethyleneimine (PEI) were purchased from Beijing Solarbio Co., Ltd. Calcium chloride, potassium chloride and sodium hydroxide were purchased from Tianjin Kermel Chemical Reagent Co., Ltd and glutaraldehyde (GA) (50\%) was purchased from Shanghai Aladdin Biochemical Technology Co., Ltd. American ginseng purchased from Jinlin province and ginsenoside Rb1 was extracted in our lab. All other fine chemicals were of Analar or equivalent quality.

\subsection{Methods}

2.2a Preparation of gel beads: Three types of gel solutions were prepared by dissolving either sodium alginate, $K$-carrageenan, or chitosan in distilled water to get a final concentration of $2 \%(\mathrm{w} / \mathrm{v})$; gel solutions were left undisturbed to disengage bubbles before use. Afterwards, gel solutions (alginate, $K$-carrageenan and chitosan) were dropped into three hardening solutions (calcium chloride solution $2 \%$ (w/v), $\mathrm{KCl} 2 \%(\mathrm{w} / \mathrm{v})$ and $\mathrm{NaOH} \mathrm{5 \%} \mathrm{(w/v)),} \mathrm{by} \mathrm{using} \mathrm{a}$ syringe. The resulting uniform gel beads (diameter $2 \mathrm{~mm}$ ) were allowed to harden for $3 \mathrm{~h}$. Then the gel beads were ready for immobilization [16].

2.2b Activation of gel beads: Activation of gel beads was carried out by soaking the generated beads into PEI for appropriate time and then washed twice with distilled water to remove excess PEI. After that, gel beads were soaked in GA solution for appropriate time and washed carefully with distilled water to remove unbound GA, and the beads were ready for immobilization (figure 1).

2.2c Determination of snailase activity: As ginsenoside $\mathrm{Rb} 1$ transformed to $\mathrm{Rd}$ and glucose, determination of snailase activity was done by using the dinitrosalicylic acid (DNS) method. Snailase activity was measured by mixing $100 \mu \mathrm{l}$ free enzyme (or $0.1 \mathrm{~g}$ beads of immobilized enzyme) with $1 \mathrm{ml}$ ginsenoside $\mathrm{Rb} 1$ ( $2 \mathrm{mg} \mathrm{ml}^{-1}$ in acetate buffer, $\left.\mathrm{pH} 5\right)$ and incubating it for $60 \mathrm{~min}$ at $50^{\circ} \mathrm{C}$. To stop the reaction, $2 \mathrm{ml}$ of DNS was added, boiled for $5 \mathrm{~min}$ and then cooled to room temperature. Blank is prepared by substituting the enzyme solution with buffer and repeating all the reaction steps. The absorbance was read at $\lambda=540 \mathrm{~nm}$ by using a spectrophotometer. One unit of enzyme activity was equivalent to the amount of enzyme required to produce $1 \mu \mathrm{mol}$ glucose per min. 
2.2d Immobilization of snailase: For snailase immobilization, $1 \mathrm{~g}$ of the previously treated gel beads was loaded with $4 \mathrm{ml}$ of $100 \mathrm{mM}$ acetate buffer ( $\mathrm{pH}$ 5) containing $10 \mathrm{U}$ snailase. This mixture was agitated for $16 \mathrm{~h}$ at room temperature using a roller stirrer. At the end of incubation time beads were washed well with buffer, and directly assayed for snailase activity.

2.2e Characterization of gel beads: For gel bead characterization, different gel formulations, carrageenan, carrageenan + PEI, carrageenan + PEI + GA and carrageenan + PEI + GA + enzyme, were evaluated by using Fourier transform infrared spectroscopy (FT-IR-850, Tianjin Gangdong Sci \& Tech Development Co., Ltd, China). FT-IR spectra were obtained in the wavelength region of $400-4000 \mathrm{~cm}^{-1}$ at ambient temperature.

2.2f Optimization of ginsenoside biotransformation: To validate the efficiency of the biotransformation process of ginsenoside for use in industries, the following experiments were conducted.

$2.2 \mathrm{~g}$ Effect of $\mathrm{pH}$ on ginsenoside biotransformation: To determine the optimum $\mathrm{pH}$ for ginsenoside biotransformation, both free and immobilized snailase were incubated into $1 \mathrm{ml}$ of $2 \mathrm{mg} \mathrm{ml}^{-1}$ of ginsenoside dissolved in acetate buffer with different $\mathrm{pH}$ values $(\mathrm{pH} 3.0-6.0)$ at $50^{\circ} \mathrm{C}$ for $60 \mathrm{~min}$ respectively. The data were normalized to $100 \%$ activity. The highest enzyme activity was expressed as $100 \%$, and each $\mathrm{pH}$ was expressed as a percentage of $100 \%$ activity.

2.2h Effect of temperature on ginsenoside biotransformation: The effect of temperature on ginsenoside biotransformation was determined by carrying out the reaction at different range of temperatures $\left(30-90^{\circ} \mathrm{C}\right)$ for $60 \mathrm{~min}$. The temperature showing maximum activity was taken as optimum temperature and the other activities were expressed as a percentage of this optimum $100 \%$ activity.

$2.2 \mathrm{i} K_{\mathrm{m}}$ and $V_{\max }$ of free and immobilized snailase: Michaelis-Menten constant $\left(K_{\mathrm{m}}\right)$ and the maximum velocity $\left(V_{\max }\right)$ for immobilized and free form of snailase were determined using the Hanes-Woolf plot. The reaction was carried out using different final concentrations of ginsenoside $\mathrm{Rb} 1$ (0.3-10 mM) in $100 \mathrm{mM}$ acetate buffer of $\mathrm{pH} 5$.

2.2j Ginsenoside transformation: Ten units of free and immobilized snailase enzymes were incubated at $60^{\circ} \mathrm{C}$ for $6 \mathrm{~h}$ in $100 \mathrm{mM}$ acetate buffer of $\mathrm{pH} 5$ in the assay mixture. Samples were withdrawn at regular intervals from 1 to $6 \mathrm{~h}$ and analysed for ginsenoside hydrolysis.

2.2k Detection of ginsenoside transformation: Transformation of ginsenosides by using both free and immobilized snailase was detected by using HPLC $\mathrm{C}_{18}$-column (Zorbax
SB-C $18,250 \mathrm{~mm} \times 4.6 \mathrm{~mm}, 5 \mu \mathrm{m}$, Agilent, USA). Rb1, Rd and $\mathrm{C}-\mathrm{K}$ were taken as a reference of ginsenoside transformation. The reference compounds were accurately weighed and dissolved in methanol to produce standard stock solutions of concentration $\left(1 \mathrm{mg} \mathrm{ml}^{-1}\right)$. HPLC analysis was conducted on an Agilent 1260 with a DAD detector at $203 \mathrm{~nm}$ at $30^{\circ} \mathrm{C}$. The mobile phase consisted of $0.1 \%$ phosphoric acid-water (A) and acetonitrile (B), with an optimized linear gradient elution as follows: $0-20 \mathrm{~min}, 25-30 \% \mathrm{~B} ; 20-30 \mathrm{~min}, 30 \% \mathrm{~B}$; $30-65 \mathrm{~min}, 30-65 \% \mathrm{~B}$. The injection volume was $20 \mu \mathrm{l}$ with

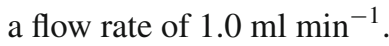

2.21 Operational stability: The operational stability of immobilized snailase onto activated carrageenan beads was checked by assay to determine its operational stability. One gram of gel beads was incubated into $1 \mathrm{ml}$ of ginsenoside at pH 5 and $50^{\circ} \mathrm{C}$ for $60 \mathrm{~min}$, and the substrate solution was assayed. The same gel beads were then washed with distilled water and re-incubated into another substrate solution; this procedure was repeated 10 times, and the initial activity was considered as $100 \%$. The relative activity was expressed as a percentage of the starting operational activity.

\section{Results and discussion}

At the beginning of this work, different types of gel beads were formed using sodium alginate, $K$-carrageenan and chitosan. $K$-carrageenan gel beads were the best carrier for snailase immobilization. Optimization of PEI and GA (concentration and $\mathrm{pH}$ ) was done and is shown in supplementary material.

Steps of preparation of gel beads as well as snailase immobilization are shown in figure 1, and the figure shows the reaction between the PEI amino group and GA aldehyde group forming Schiff's base $(-\mathrm{N}=\mathrm{CH})$. This new bond can be proven through FT-IR technique [16].

The enzyme reacted with the activated gel beads showed an obvious effect. The reaction occurred between the free $\mathrm{C}=\mathrm{O}$ group found on $\mathrm{GA}$ and the $\mathrm{NH}_{2}$ group found in the enzyme forming a $\mathrm{C}=\mathrm{N}-$ bond [17].

\subsection{Elucidation of the modified gel beads}

3.1a FT-IR spectroscopy: The FT-IR spectroscopic analysis of gel beads in different stages was carried out from 400 to $4000 \mathrm{~cm}^{-1}$ (figure 2). IR spectrum of beads showed characteristic peaks in every step of the reaction, spectra of carrageenan beads are shown in curve A. Spectra for aminated carrageenan beads showed a new broad peak at $3400 \mathrm{~cm}^{-1}$ corresponding to the $\mathrm{NH}_{2}$ group. This proves that the surface of beads become aminated with the amine group (curve B), while GA-activated beads showed two new peaks: the first one at $1640 \mathrm{~cm}^{-1}$ referred to the $\mathrm{C}=\mathrm{O}$ group of a free aldehyde end of GA, and another peak at $1730 \mathrm{~cm}^{-1}$ referring to the $\mathrm{C}=\mathrm{N}$ group which resulted from the reaction of the $\mathrm{NH}_{2}$ end groups with the GA aldehyde 


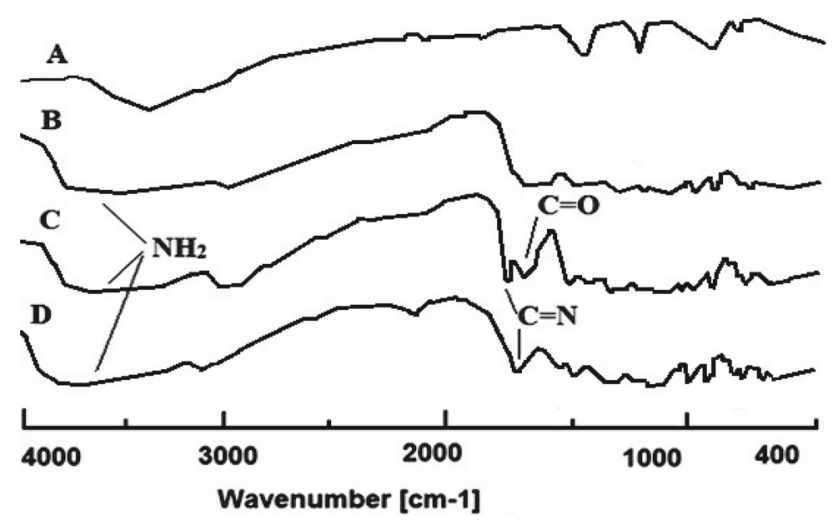

Figure 2. FT-IR for (A) carrageenan, (B) aminated carrageenan, (C) activated carrageenan and (D) enzyme immobilized on carrageenan.

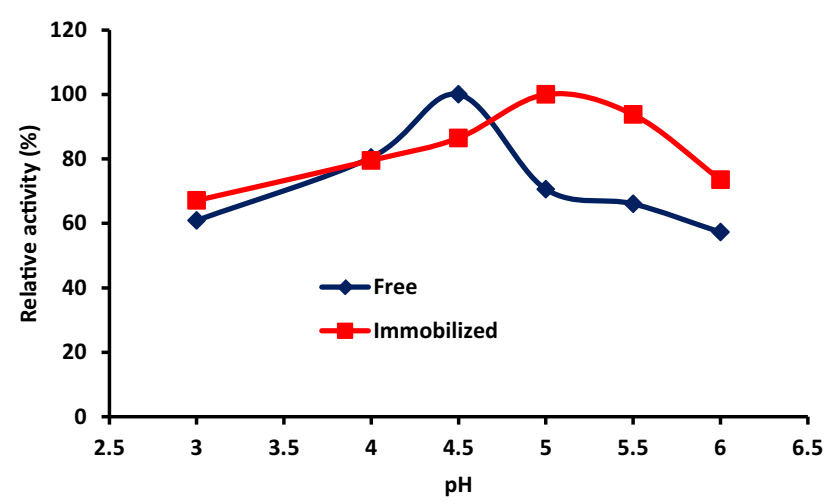

Figure 3. Optimum $\mathrm{pH}$ for free and covalently immobilized snailase onto activated gel beads for PPD transformation. The reaction was carried out at $50^{\circ} \mathrm{C}$ for $90 \mathrm{~min}$ at different $\mathrm{pH}$ values.

group (curve C). Finally, immobilized carrageenan beads show a broader peak at $3450 \mathrm{~cm}^{-1}$, referring to the increase in $\mathrm{NH}_{2}$ group's concentration. This increase is because of the enzyme $\mathrm{NH}_{2}$ group (curve D). From all of the above, it was concluded that the process of amination, activation and immobilization takes place successfully. This result was in agreement with other published results $[18,19]$.

\subsection{Optimization of biotransformation of ginsenoside using free and immobilized snailase}

3.2a Optimization of reaction $\mathrm{pH}$ for free and immobilized snailase: In this experiment we study the effect of substrate $\mathrm{pH}$ on immobilized and free enzyme. From the data illustrated in figure 3 , we observe that the optimum $\mathrm{pH}$ for free enzyme was 4.5 and it became 5-5.5 after immobilization. A noticeable change in $\mathrm{pH}$ range of immobilized enzyme was recognized as it became slightly higher and broader than the free one. This result was in agreement with Yu et al, who found that optimum biotransformation $\mathrm{pH}$ of ginsenoside was 5 and 5.5 for immobilized and free snailase, respectively [20]. This

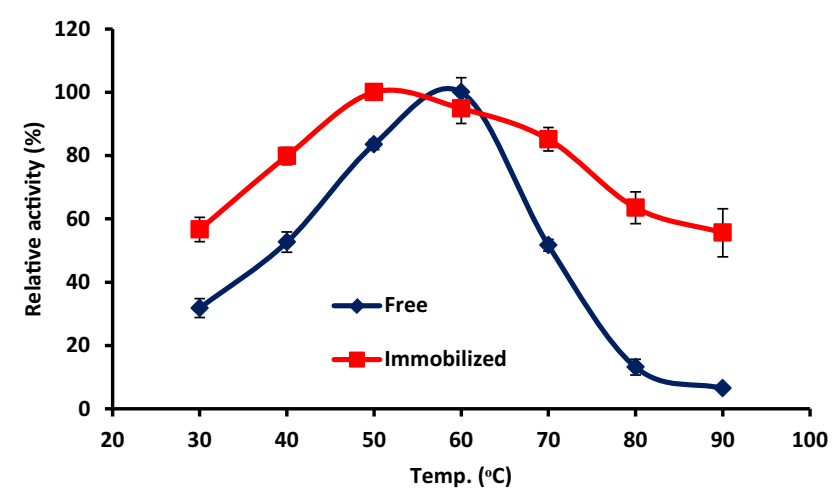

Figure 4. Optimum temperature for free and covalently immobilized snailase onto activated gel beads for PPD transformation, the reaction was carried out in $100 \mathrm{mM}$ acetate buffer of pH 5 for $90 \mathrm{~min}$.

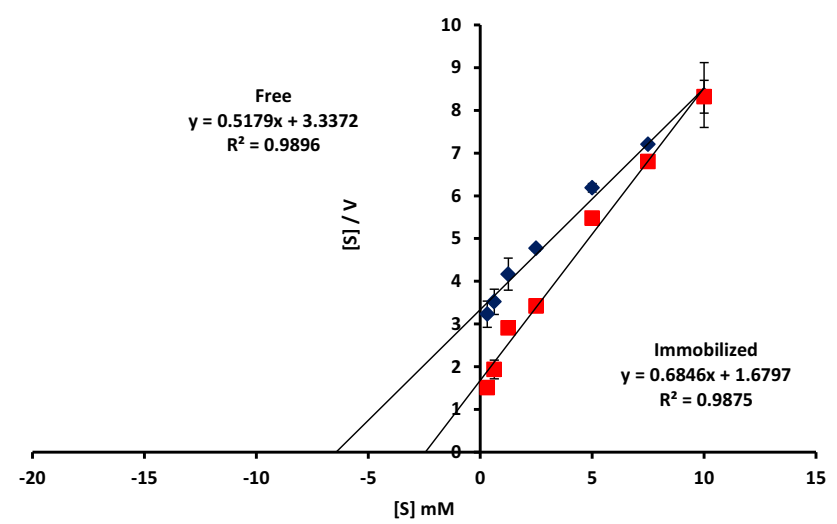

Figure 5. Kinetic parameters of free and immobilized snailase using the Hanes-Woolf plot method [20]. The reaction was carried out using different final concentrations of PPD $(0.3-10 \mathrm{mM})$ in $100 \mathrm{mM}$ acetate buffer of $\mathrm{pH} 5$ at $60^{\circ} \mathrm{C}$ for $90 \mathrm{~min}$.

means that immobilization of the enzyme makes it more stable than the free one and this stability is because of the effect of Schiff's base formation [21]. Magdy and Mohamed reported the same observation when they used aminated carrageenan beads as a carrier for enzyme immobilization [16].

3.2b Optimization of reaction temperature for free and immobilized snailase: Effect of ginsenoside Rb1 biotransformation temperature is shown in figure 4 . It is shown that the optimum temperature was 50 and $60^{\circ} \mathrm{C}$ for immobilized and free snailase, respectively. Wei et al found that optimum biotransformation temperature was $50^{\circ} \mathrm{C}$ when they used snailase in a free form [13]. Furthermore, the figure shows that the profile of immobilized enzyme became more wide and broader in a bell-shaped curve. In a temperature range of $50-70^{\circ} \mathrm{C}$, the enzyme activity is higher than $85 \%$ of its activity when compared with the free one. This broad range may be because of the low effect of environmental temperature on the immobilized enzyme as a result of covalent bond formed between the enzyme and carrier. These data are in agreement with 
Yu et al, who found that the optimum temperature of immobilized snailase is $60^{\circ} \mathrm{C}$ [20]. Chen et al suggested that the enzyme behaviour along the immobilization process is attributed to the covalent linkage between the enzyme and gel beads [22].

3.2c Effect of substrate concentration on the activity of free and immobilized snailase: The kinetic parameters regarding the substrate concentration effect for both immobilized

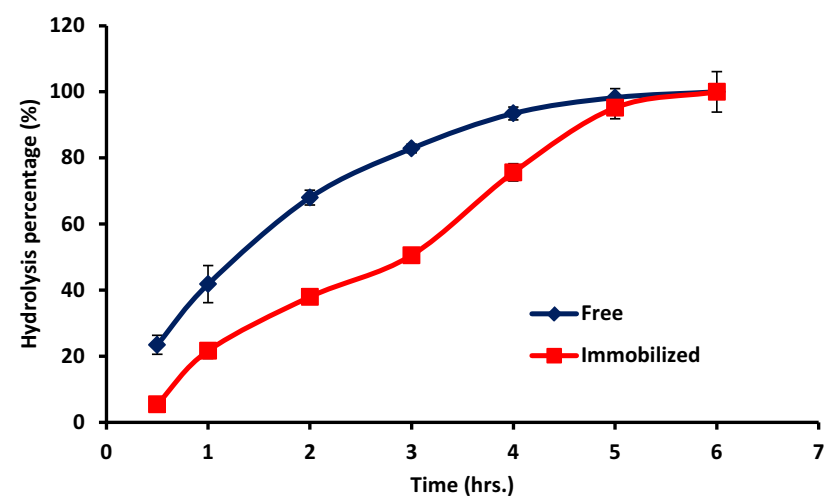

Figure 6. Full conversion of substrate using free and immobilized snailase onto activated gel beads. The reaction was carried out in $100 \mathrm{mM}$ acetate buffer of $\mathrm{pH} 5$ at $60^{\circ} \mathrm{C}$. and free snailase were calculated using the Hanes-Woolf plot method. Figure 5 shows that $K_{\mathrm{m}}$ of immobilized enzyme was $2.45 \mathrm{mM}$, became lower than $K_{\mathrm{m}}$ of the free one, $6.44 \mathrm{mM}$, a decrease of $K_{\mathrm{m}}$ value leading to a faster hydrolysis reaction rate. The $K_{\mathrm{m}}$ decreases if the support and the substrate have opposite electric charges [23]. So we can define $K_{\mathrm{m}}$, Michaelis constant, as a measure of the affinity of the enzyme for its substrate (as $K_{\mathrm{m}}$ decreases, the enzyme affinity for the substrate increases) [24,25].

Figure 5 shows that there is no substrate or product inhibition observed during our experiment (straight line of the Hanes-Wolf) with the increase of substrate concentration up to $10 \mathrm{mM}$. On the other hand, the maximum reaction velocity values, $V_{\max }$, for immobilized enzyme were determined; it decreased from 1.9 for the free enzyme to 1.4 for the immobilized one. The enzyme's ability of restriction may be undergoing conformational changes intrinsic to the enzymesubstrate interactions due to the immobilization process; this restriction would cause the $V_{\max }$ of the immobilized enzyme to decrease [26].

3.2d Ginsenoside biotransformation: Full conversion of ginsenoside $\mathrm{Rb} 1$ using free and immobilized snailase is shown in figure 6; from this figure we notice that the free enzyme is faster than the immobilized one for substrate conversion. This is because the free enzyme reacts with the substrate easily

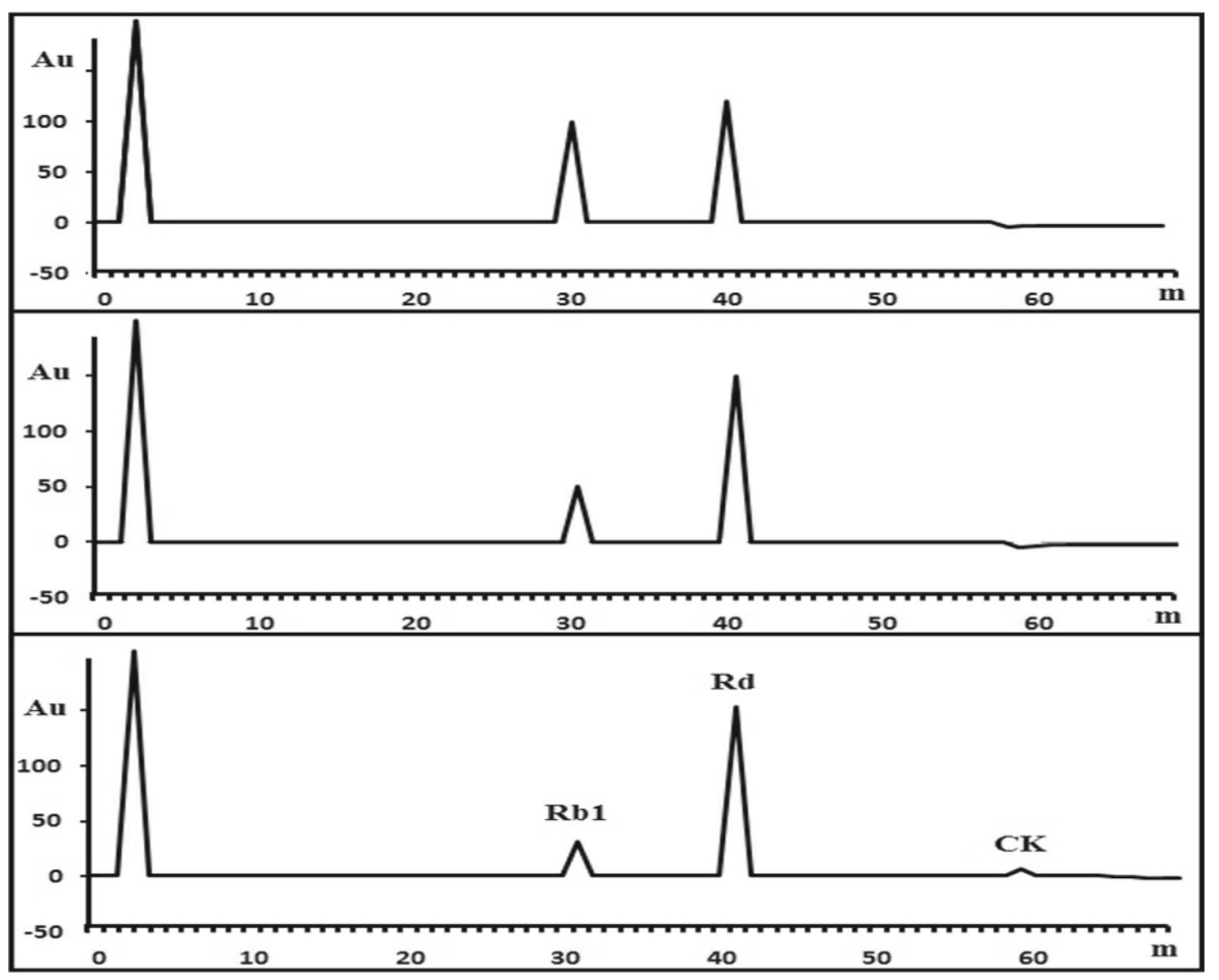

Figure 7. HPLC analysis of PPD transformations by using snailase. 


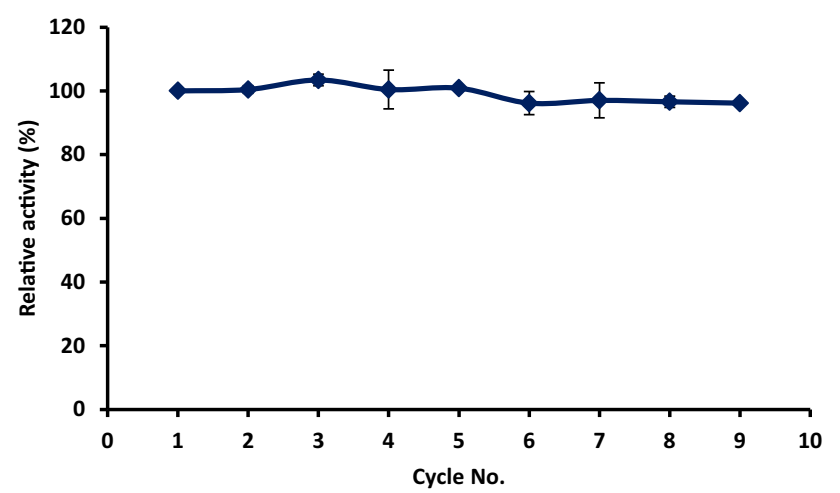

Figure 8. Operational stability of immobilized snailase. Beads containing enzyme were assayed and afterwards, it was washed carefully with buffer and re-assayed. This reaction was carried out 10 times.

while the immobilized enzyme is restricted and needs more time to react with all the substrate regarded to the time required for the immobilized enzyme to retain its better 3D conformation inside the gel beads [19].

Figure 7 presents the HPLC analysis of transformation of ginsenoside $\mathrm{Rb} 1$. The charts confirmed that ginsenoside $\mathrm{Rb} 1$ is converted to $\mathrm{Rd}$ and $\mathrm{C}-\mathrm{K}$ by immobilized snailase.

In the HPLC chart analysis, it is shown that the ginsenoside $\mathrm{Rd}$ was detected after $1.5 \mathrm{~h}$ of biotransformation, while $\mathrm{C}-\mathrm{K}$ was produced after $3 \mathrm{~h}$. It is also reported in other references $[8,27,28]$ that a transformation path ginsenoside $\mathrm{Rb} 1 \rightarrow \mathrm{Rd} \rightarrow \mathrm{C}-\mathrm{K}$ is involved in the transformation of $-\mathrm{Rb} 1$. Ginsenoside $\mathrm{Rg} 3$ or $\mathrm{Rh} 2$ cannot be transformed from $-\mathrm{Rb} 1$ during snailase enzymolysis.

3.2e Reusability of snailase immobilized onto carrageenan gel bead surface: One of the most important requirements for industrial enzyme applications is the enzyme operational stability. It is one of the most important parameters which is used to evaluate the immobilization process. The reusability of snailase immobilized onto activated carrageenan gel beads was evaluated (figure 8 ). The data show that the enzyme retained its stability up to six cycles. Also, it retained $96 \%$ of its activity after 10 cycles. These data are higher than data obtained by Peng et al [29], who recorded only 53\% retained activity after only three times for entrapment of snailase in alginate-barium microsphere and $74 \%$ retained activity after five times for crosslink-embedded snailase [30].

\section{Conclusions}

In this work we succeeded in immobilizing snailase enzyme on activated carrageenan beads activated by PEI and GA and applying it in ginsenoside transformation. The optimum $\mathrm{pH}$ and temperature for snailase enzyme were determined. Ginsenoside $\mathrm{Rb} 1$ biotransformation by immobilized snailase into
$\mathrm{C}-\mathrm{K}$ was checked by using HPLC after $3 \mathrm{~h}$ of reaction time. The efficiency of immobilized snailase onto carrageenan gel beads was tested by reusing the immobilized enzyme up to 10 times with $96 \%$ of its initial activity. The reusability of the immobilized enzyme is considered as an important parameter in the immobilization process for economic and biotechnical benefits and opens the possibility of different industrial applications.

\section{Acknowledgements}

The authors want to thank Prof Ghada Awad and Prof Mona Esawy for their generous help in revising the paper's language.

\section{References}

[1] Seong-Eun P, Chang-Su N, Seon-A Y, Seung-Ho S and HongSeok S 2017 J. Ginseng Res. 4136

[2] Deqiang D O U, Wei L I, Na G U O, Rui F U, Yuping P E I, Kazuo K et al 2006 Chem. Pharm. Bull. 54751

[3] Chun-Ying L, Rui-Xin Z, Chang-Kai S, Ying-Hua J, HongShan Y, Tian-Yang Z et al 2015 J. Ginseng Res. 39221

[4] Dou D Q, Hou W B and Chen Y J 1998 Planta Med. 64585

[5] Zheng X, Jia L, Zhixun Z, Yingying L, Deqiang D and Jinming Z 2013 Nat. Prod. Res. 271271

[6] Bae E A, Shin J E and Kim D H 2005 Biol. Pharm. Bull. 28 1903

[7] Cui C H, Kim S C and Im W T 2013 Appl. Microbiol. Biotechnol. 97649

[8] Hasegawa H, Sung J H, Matsumiya S and Uchiyama M 1996 Planta Med. 62453

[9] Park C S, Yoo M H, Noh K H and Oh D K 2010 Appl. Microbiol. Biotechnol. 879

[10] Hasegawa H 2004 J. Pharmacol. Sci. 95153

[11] Cui C H, Liu Q M, Kim J K, Sung B H, Kim S G, Kim S C et al 2013 Appl. Environ. Microbiol. 795788

[12] Jin X F, Yu H S, Wang D M, Liu T Q, Liu C Y, An D S et al 2012 J. Microbiol. Biotechnol. 22343

[13] Wei L, Ming Z, Yi-Nan Z, Jing L, Ying-Ping W and Yun-Jing W 2011 Molecules 1610093

[14] Franzreb M, Siemann-Herzberg M, Hobley T J and Thomas O R 2006 Appl. Microbiol. Biotechnol. 70505

[15] Přenosil J E, Kut Ö M, Dunn I J and Heinzle E 2000 Practical methods for biocatalysis and biotransformations (UK: Wiley$\mathrm{VCH}$ Verlag $\mathrm{GmbH} \& \mathrm{Co} . \mathrm{KGaA}$ )

[16] Magdy M E and Mohamed E H 2014 Biomed. Res. Int. 2014 817985

[17] Ying Y, Xiaoning L, Xiao K R, Mohamed E H and Deqiang D 2016 J. Mol. Catal. B: Enzym. 133 S525

[18] Magdy M E, Mohamed E H and Ghada E A A 2013 J. Colloid Sci. Biotechnol. 227

[19] Tamer M T, Mohamed A H, Ahmed M O, Walid M A B, Mohamed E H, Muhammad E A E et al 2016 Process Biochem. 511721

[20] Yu Z, Liu Q, Cui L, Jia X, Zhang Z and Jin X 2014 Chin. Tradit. Herb Drugs 453092 
[21] Zhou J 2010 J. Agric. Food Chem. 586741

[22] Chen S H, Yen Y H, Wang C L and Wang S L 2003 Enzyme Microb. Technol. 33643

[23] De maio A, El-Masry M M and Mita D G 2003 J. Mol. Catal. B: Enzym. 21239

[24] Azevedo A M, Fonseca L P and Prazeres D M F 1999 J. Chem. Technol. Biotechnol. $\mathbf{7 4} 1110$

[25] Ghada E A A, Hala R W, Abeer A A E A and Mohamed E H 2017 Colloid Polym. Sci. 295495
[26] Wahba M I and Hassan M E 2015 Biopolymers 103675

[27] Hasegawa H, Sung J H and Benno Y 1997 Planta Med. 63 436

[28] Wang C Z, Kim K E, Du G J, Qi L W, Wen X D, Li P et al 2011 Am. J. Chin. Med. 391161

[29] Peng J, Ma Y, Chen Y, Liu C, Gao X and Zhou J 2015 Chin. Tradit. Herb Drugs 223326

[30] Peng J, Ma Y, Chen Y, Liu C, Gao X and Zhou J 2015 Acta Pharm. Sin. 121652 